\title{
Exportación de servicios turísticos: ¿un sector estratégico para enfrentar el cambio climático en Costa Rica?
}

DOI: https://doi.org/10.21158/01208160.n0.2020.2738

Fecha de recepción: 27 de mayo de 2020

Fecha de aprobación: 24 de julio de 2020

Fecha de publicación: 03 de diciembre de 2020
Marjorie Hartley-Ballestero ${ }^{1}$ Universidad Nacional - Costa Rica marjorie.hartley.ballestero@una.ac.cr

Kerlyn Suárez-Espinoza ${ }^{2}$ Universidad Nacional - Costa Rica kerlyn.suarez.espinoza@est.una.ac.cr

Cómo citar este artículo / To reference this article / Comment citer cet article / Para citar este artigo:

Hartley-Ballestero, M.; Suárez-Espinoza, K. (2020). Exportación de servicios turísticos: ¿un sector estratégico para enfrentar el cambio climático en Costa Rica? Revista Escuela de Administración de Negocios, Edición especial 2020, 53 - 70. DOI: https: // doi.org/10.21158/01208160.n0.2020.2738

\section{Resumen}

La actividad turística costarricense se ha convertido en uno de los principales productos de exportación y en una estrategia de desarrollo sostenible, dada su estrecha relación con los espacios ambientales existentes y en razón a las características de los territorios en los que se prestan estos servicios. El turismo se considera uno de los sectores económicos más vulnerables a la variación del clima, pues muchos destinos dependen de las condiciones ecológicas — por ejemplo, el turismo de sol y playa o de recursos ambientales — como las zonas protectoras o parques nacionales. En este contexto, el artículo busca evidenciar elementos de mejora ambiental que contribuyan a la sustentabilidad actual y futura de los servicios de turismo receptor, con el conocimiento de que la política de adaptación para enfrentar el cambio climático no tiene acciones explícitas orientadas al sector turismo. La investigación muestra que es necesaria la formulación de política pública explícita dirigida a la adaptación y mitigación del sector turismo, y no solo para los espacios naturales que explotan los servicios ecosistémicos ofrecidos por la biodiversidad que posee el país. Además, desde el punto de vista de la economía circular, se han dado importantes avances en algunos indicadores relacionados con la conservación, la resiliencia, el uso y el consumo del recurso hídrico, alianzas público-privadas, redes de apoyo y otros que favorecen la sostenibilidad de comunidades y territorios. Esto evidencia la importancia estratégica del sector para enfrentar el cambio climático y la necesaria incorporación de acciones más robustas en este objetivo.

Palabras clave: servicios turísticos; actividad turística; sector turismo; servicios de turismo sustentable; economía circular; desarrollo sostenible; cambio climático.

\footnotetext{
${ }^{1}$ Investigadora de la Escuela de Economía de la Universidad Nacional, Costa Rica. Economista con especialidad en Desarrollo Sostenible y Economía Ecológica por la Universidad Nacional de Costa Rica. ORCID: 0000-https://orcid.org/0000-0003-17516524

2 Estudiante de licenciatura de la Escuela de Economía de la Universidad Nacional, Costa Rica. Bachiller en Economía por la Universidad Nacional de Costa Rica. ORCID: https://orcid.org/0000-0001-9862-7909
} 


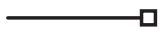

\section{Abstract}

The tourism activity in Costa Rica has become one of the principal export products and a sustainable development strategy, given its close relationship with the existing environmental spaces and because of the characteristics of the territories where these services are provided. Tourism is one of the most vulnerable economic sectors to climate variation, since many destinations depend on ecological conditions - for example, sun and beach tourism or the environmental resources of a tourist destination - such as protective areas or national parks. In this context, this article seeks to highlight elements of environmental improvement that contribute to the current and future sustainability of inbound tourism services, bearing in mind that the adaptation policy to address climate change does not have explicit actions aimed at the tourism sector. The research shows it is necessary to formulate explicit public policy aimed at the adaptation and mitigation in the tourism sector, and not only for natural areas that exploit the ecosystem services offered by the biodiversity of the country. In addition, from the point of view of the circular economy, important advances have been made in some indicators related to conservation, resilience, use and consumption of water resources, public-private alliances, support networks, and others that favor the sustainability of communities and territories. This shows the strategic importance of the sector in confronting climate change and the need to incorporate more robust actions in this aim.

Keywords: tourism services; tourism activity; tourism sector; sustainable tourism services; circular economy; sustainable development; climate change.

\section{Exportação de serviços turísticos: um setor
$\square \quad$ estratégico para enfrentar as mudanças climáticas na Costa Rica? \\ Resumo}

A atividade turística da Costa Rica tornou-se um dos principais produtos de exportação e uma estratégia de desenvolvimento sustentável, por sua estreita relação com os espaços ambientais existentes e pelas características dos territórios onde esses serviços são prestados. $\mathrm{O}$ turismo é considerado um dos setores econômicos mais vulneráveis à variação climática, pois muitos destinos dependem de condições ecológicas - por exemplo, turismo de sol e praia ou recursos ambientais - como zonas de proteção ou parques nacionais. Nesse contexto, o artigo busca mostrar elementos de melhoria ambiental que contribuem para a sustentabilidade atual e futura dos serviços de turismo receptivo, com o conhecimento de que a política de adaptação para enfrentar as mudanças climáticas não possui ações explícitas voltadas para o setor turístico. A pesquisa mostra que é necessário formular uma política pública explícita voltada para a adaptação e mitigação do setor turístico, e não apenas para os espaços naturais que exploram os serviços ecossistêmicos oferecidos pela biodiversidade que tem o país. Além disso, do ponto de vista da economia circular, tem havido avanços importantes em alguns indicadores relacionados à conservação, resiliência, uso e consumo de recursos hídricos, parcerias público-privadas, redes de apoio e outros que favorecem a sustentabilidade de comunidades e territórios. Isso mostra a importância estratégica do setor para enfrentar as mudanças climáticas e a necessária incorporação de ações mais robustas nesse objetivo.

Palavras-chave: serviços turísticos; atividade turística; setor de turismo; serviços de turismo sustentável; economia circular; desenvolvimento sustentável; mudança climática. 


\section{Exportation de services touristiques: secteur stratégique pour faire face au changement climatique au Costa Rica?}

\section{Résumé}

Lactivité touristique du Costa Rica est devenue l'un des principaux produits d'exportation du pays et une stratégie de développement durable du fait de sa relation étroite et privilégiée avec l'environnement et en raison des caractéristiques des territoires dans lesquels sont offerts ces services. Le tourisme est l'un des secteurs économiques les plus vulnérables aux variations climatiques dans la mesure où de nombreuses destinations dépendent de conditions environnementales optimales - le tourisme de détente, à la mer ou à la montagne, le tourisme vert, les espaces protégés, les parcs nationaux. Cet article révèle l'importance des éléments nécessaires à une prise de conscience environnementale contribuant à la durabilité et protection de l'environnement de la part des opérateurs touristiques récepteurs, dans la mesure où les politiques d’adaptation au changement climatique n'incluent pas d'actions explicites pour le secteur touristique. Cette investigation révèle également la nécessité de création de politiques publiques globales, nationales et explicites visant à faire évoluer le secteur touristique vers une plus grande protection de l'environnement, des écosystémes et de la biodiversité du Costa Rica. Par ailleurs, en ce qui concerne l'économie circulaire, nous constatons que des avancées importantes ont eu lieu en terme de conservation, de résilience, d'utilisation et de consommation des ressources hydriques, de partenariats publicprivé favorisant la durabilité des communautés et des territoires. Cette prise de conscience montre l'importance stratégique du secteur du tourisme face au changement climatique et à la nécessaire mise en place d'actions percutantes pour atteindre ces objectifs.

Mots-clés: services touristiques; activité touristique; secteur du tourisme; services de tourisme durable; économie circulaire; développement durable; changement climatique. 


\section{Introducción}

A partir de la década de los noventa, Costa Rica Aha impulsado una estrategia de desarrollo orientada a la apertura económica y la participación en los procesos de globalización tanto comercial como financiera. En esta tarea la creación de regímenes especiales de comercio exterior y la firma de tratados comerciales con diversos países han contribuido a la diversificación del tipo de negocios internacionales, entre los que se destacan los servicios turísticos, así como los servicios empresariales y las actividades afines (Pierce, Ramírez y Sandí, 2017).

Para el periodo 2012-2014, la composición porcentual de las exportaciones de servicios corresponde, principalmente, a actividades tales como hospedaje, alimentación, transportes $y$ otros servicios empresariales — consultorías y administrativos-, así como a telecomunicaciones, informática e información. A su vez, la exportación de viajes corresponde, aproximadamente, al $43 \%$ del total de exportaciones de servicios. Dentro de este rubro también se ha experimentado diversificación, debido a que los viajes se pueden clasificar de la siguiente manera: cruceros -0,3 \%-, transfronterizos - $1,1 \%$-, viajes por educación $-7,9 \%$-, viajes por salud $-11,2 \%$ - viajes por negocios $-14,3 \%-$ y viajes personales - que corresponde a un $65,3 \%$ para el 2014- (Pierce et al., 2017).

La actividad turística costarricense se ha convertido en uno de los principales productos de exportación $y$ en una estrategia de desarrollo sostenible, al encontrarse estrechamente vinculada con las áreas de conservación existentes - cerca del $54 \%$ de territorio nacional $-y$ con la riqueza natural de otros espacios como lo son playas, montañas y la gran diversidad biológica que albergan.

La industria turística nacional y de exportación es un importante sector para la economía costarricense, tal como se explica en páginas posteriores, pero además por su vinculación directa con los ecosistemas existentes. De igual forma, debido a la importancia de que estos continúen ofreciendo los bienes y servicios que sostienen la actividad económica y social, se convierten, al mismo tiempo, en un sector estratégico para enfrentar el cambio climático.

Se tiene así que la actividad turística, en general, se ve fuertemente impactada por la pérdida o degradación de espacios ambientales ocasionada por el cambio climático. Inundaciones que destruyen infraestructura vial o edificaciones, pérdida de especies por aumento en la temperatura, playas invadidas por algas que impiden el disfrute de los bañistas y otros tantos ejemplos que se pueden anotar. Con estos pocos se evidencia que la actividad turística es de los sectores económicos más vulnerables a la variación del clima, pues muchos destinos dependen de las condiciones ecológicas.

No obstante, al igual que toda actividad económica — de forma directa o indirecta-, el turismo contribuye al calentamiento global del planeta en la medida en que es un sector interconectado con otras actividades como la aviación, el transporte terrestre, el alojamiento y el comercio al por menor. Los impactos proceden, principalmente, del incremento continuo en el volumen de desplazamientos, en su mayoría a través del transporte aéreo - emisión del gas de efecto invernadero o GEI-, y, por otra parte, el aumento en el consumo de agua y energía por alojamiento y mantenimiento de instalaciones turísticas. Se estima que el turismo es el responsable del $5 \%$ de las emisiones de GEI mundial, el $4 \%$ proviene del transporte y el $1 \%$ del alojamiento y otras actividades turísticas.

En este sentido, se puede afirmar que los servicios turísticos, paradójicamente, contribuyen con los procesos de cambio climático, pero además se ven fuertemente perjudicados por las variaciones en el clima. De manera que el éxito en las medidas para enfrentar el cambio climático fortalece los servicios 
turísticos y garantiza su sostenibilidad. En esta medida también el sector es estratégico a fin de enfrentar el cambio climático en el país.

La investigación parte del hecho de que el turismo es una actividad económica que no se escapa del mecanismo lineal de la producción enfocado en la extracción, la producción, el consumo y el desecho. Por eso, como una alternativa a lo anterior, la economía circular (EC) representa una oportunidad para que la industria turística alcance mayores niveles de sostenibilidad y productividad.

En particular, el enfoque de la economía circular aporta importantes elementos para el análisis de la sostenibilidad de la actividad turística, al contribuir con elementos a nivel micro como lo son la capacidad del reciclaje de productos, la reutilización de materias y el uso de energías limpias o renovables. Desde el mesonivel, por el papel de las instituciones para favorecer y facilitar los procesos micro. $\mathrm{Y}$ a nivel macro, por la creación de las tareas que conduzcan a nuevas formas de hacer negocios, a la innovación de las comunidades para hacerlas más sostenibles; y que, a su vez, ofrezcan un mayor disfrute de la experiencia turística.

Así, el análisis de la relación entre la EC y el turismo constituye un importante aporte al conocimiento para mejorar la eficiencia de la industria turística. Además, desde el punto de vista económico, puede contribuir a la disminución de costos y al aumento del valor agregado, proporciona ventajas competitivas, crea empleos e incrementa la productividad de las empresas. También constituye una oportunidad para mejorar la imagen y la responsabilidad social del sector.

En este contexto, la investigación plantea identificar oportunidades de mejora ambiental que contribuyan con la sustentabilidad actual y futura de los servicios de turismo receptor, desde la EC. Con este fin, en el segundo apartado se abordan los aspectos metodológicos aplicados en esta investigación. En el apartado tres se describe la evolución del peso económico que ha tenido la actividad turística en el país y lo que la hace un sector estratégico para el desarrollo.

En el cuarto apartado se describen los impactos causados por el cambio climático sobre la actividad turística costarricense, así como los efectos que genera el sector y contribuyen al calentamiento global. Posteriormente, se ofrece un análisis de las acciones de mitigación y adaptación por parte de la política pública para enfrentar el cambio climático y contribuir al desarrollo sostenible de Costa Rica; en este marco se presentan algunos indicadores de economía circular que permiten analizar el desempeño del sector. Finalmente, el apartado sexto presenta la discusión y los resultados sobre lo investigado. 


\section{Estrategia metodológica}

$\mathrm{L}$ a investigación se lleva a cabo a partir de la revisión de fuentes secundarias, en las que se destacan los planes de desarrollo turístico para el 2030. Dado el fuerte vínculo de las áreas de conservación nacionales y el turismo, también se revisan las políticas de biodiversidad y adaptación al cambio climático planteadas por Costa Rica. Esta revisión se realiza en el marco de los Objetivos del Desarrollo Sostenible (ODS) de la ONU (2019) que Costa Rica ha suscrito e iniciado en su trabajo, así como el correspondiente ajuste de políticas, programas y proyectos en diversos sectores.
Se han revisado, además, las bases de datos existentes y generadas por el Banco Central de Costa Rica (BCCR) para la construcción de la cuenta satélite de turismo. Con estos y otros datos se construyen algunos indicadores de economía circular con el fin de analizar el avance hacia la sustentabilidad del sector. A la luz de lo anterior, se presentan recomendaciones de política para contribuir con la sustentabilidad del turismo receptor.

\section{Evolución de la participación del turismo receptor en la creación de riqueza}

$\mathrm{E}$ n Costa Rica, el turismo ha tomado protagonismo en los últimos años y se ha convertido en una actividad importante en la creación de riqueza. El aporte de este servicio al PIB se calcula en la cuenta satélite de turismo con estándares que permiten la comparabilidad entre años. Así el Instituto Costarricense de Turismo - ICT (s. f. a) reporta que para el 2016 el turismo receptor contribuyó de forma directa con un $6,3 \%$ del PIB, mientras que de manera indirecta aportó el 8,2\%. La contribución en términos de divisas es de 3638,6 millones de dólares americanos al mismo año.

Así mismo, Comex (2019) asegura que los servicios turísticos representaron para el 2017, aproximadamente, el $16 \%$ de la inversión extranjera directa total, posicionándose en el tercer lugar, después de la inversión extranjera directa de la industria manufacturera y los servicios.

La tendencia creciente y el aporte a la riqueza también se observan en el mercado laboral. En el 2016 el número de empleados del sector alcanzó 317316 personas.
El crecimiento promedio anual se estima en un $3 \%$ y representa el 13,2\% del empleo nacional (BCCR, s. f.). Las actividades turísticas que más contribuyen con el empleo son: los servicios de provisión de alimentos y bebidas con $29 \%$, los servicios de enseñanza aportan el $19 \%$ y los servicios de transporte de pasajeros por carretera el $17 \%$. Se destacan, además, los servicios de atención de la salud humana y de asistencia social y alojamiento (BCCR, s. f.).

En relación con el número de establecimientos en la industria turística, para el 2016 se reportaron, aproximadamente, 21664 y se distribuyeron de manera similar al número de ocupados, en el que los servicios de provisión de alimentos y bebidas representaron un $34 \%$, los servicios de atención de la salud humana y asistencia social un $32 \%$, los servicios de alojamiento para visitantes un $12 \%$ y los servicios de transporte de pasajeros por carretera un $7 \%$ del total de empresas (BCCR, s. f.).

Para el mismo año, 2114865 personas se trasladaron en avión, mientras que por vía terrestre 799824 . 
Por último, por vía acuática fueron 25824 (BCCR, s. f.). Esto evidencia la riqueza generada con otras actividades asociadas al turismo.
Así, el turismo receptor se constituye en uno de los principales pilares de la economía costarricense, ya que aporta ingresos directos e indirectos, así como genera empleo y divisas.

\section{Cambio climático y turismo en Costa Rica}

$\mathrm{E}^{\mathrm{i}}$ Instituto Costarricense de Turismo (ICT) asegura que las tres principales categorías del espacio turístico en el país son: los parques y las reservas naturales, la zona marítimo-terrestre - playas - y los territorios urbano-regionales. Todos estos sitios experimentan un incremento del $1 \%$ en la temperatura, un fenómeno que tiene un efecto directo sobre las actividades productivas y sectores como la agricultura, el recurso hídrico —el abastecimiento de agua potable - y la biodiversidad; estas dos últimas íntimamente relacionadas con el turismo (Schatan, Montiel y Romero, 2010). Evidentemente, los efectos climáticos que experimenten estos espacios incidirán en las actividades productivas que albergan, como lo es el turismo.

Entre los principales eventos climáticos que afectan las actividades turísticas se presentan las variaciones interanuales en los patrones de lluvias. Este comportamiento genera estrés hídrico a causa de la alta dependencia de las actividades socioculturales, productivas -agropecuarias- y turísticas con respecto a los regímenes de lluvias. Los impactos directos se evidencian en la reducción de la oferta hídrica para el consumo humano, en su mayoría en las regiones Central, Pacífico y Chorotega. Este déficit de precipitaciones genera sequías, en especial en la provincia de Guanacaste en la región Chorotega, con alta actividad turística (Minae y IMN, 2018).

Soto (2013), por su parte, indica que, por ejemplo, comunidades del cantón de Nicoya en la provincia de Guanacaste, con alta actividad turística, experimentan escasez de agua de alrededor de un $25 \%$. Además, los pozos que abastecen los acueductos están en muy bajo nivel. Mientras ocurre esta sequía, el sector turismo incrementa la demanda del recurso, pasando de 4011 litros por segundo en el 2013 a 4504 en el 2015 (Reyes, 2016).

Las autoridades advierten, además, que los espacios turísticos se están viendo afectados por las amenazas climáticas de manera directa o indirecta, a través de las repercusiones de eventos hidrometeorológicos que causan daños y pérdidas en infraestructura, transporte, biodiversidad y aumento en el nivel promedio del mar (Minae y IMN, 2018).

En un informe reciente, la Comisión Nacional de Prevención de Riesgos y Atención de Emergencias estima pérdidas por eventos hidrometeorológicos extremos entre el 2005 y el 2017 por USD 2210 millones en los rubros de infraestructura, servicios y producción (Minae y IMN, 2018). Las pérdidas son ocasionadas por huracanes, sistemas de baja presión, tormentas y ondas tropicales, entre otros fenómenos.

En relación con los ecosistemas, las autoridades costarricenses advierten sobre la reducción en algunos elementos de su biodiversidad tales como manglares, arrecifes, pastos marinos, playas arenosas, lagunas y pantanos. Estos espacios constituyen importantes atractivos turísticos que se han degradado por causas atribuibles, en parte, a un inadecuado uso del territorio y su biodiversidad (Minae, Sinac, Conagebio y Fonafifo, 2018).

Además, según el Ministerio de Ambiente, Energía y Telecomunicaciones (2015), el desarrollo de infraestructura turística es uno de los responsables de la pérdida de cobertura e integridad de ecosistemas marino-costeros, y los servicios turísticos forman parte de los causantes de la problemática de la calidad sanitaria de las playas, esteros y ríos. Otros efectos atribuidos a la actividad turística son las emisiones de $\mathrm{CO} 2$ generadas por el transporte aéreo de pasajeros 
y la carga internacional en los dos principales aeropuertos del país, las cuales se estiman para el 2012 en 558800 toneladas de CO2 equivalente (BlancoSalas, 2015, p. 48).
Considerando todos los medios de transporte utilizados por la industria turística, así como el alojamiento y otras actividades asociadas, la tabla 1 presenta la estimación de las emisiones del sector para el periodo 2010-2018.

Tabla 1. Costa Rica: emisiones totales y del sector turístico costarricense. Periodo 2010-2017

\begin{tabular}{|c|c|c|c|c|}
\hline Año & $\begin{array}{c}\text { Emisiones de } \mathrm{CO}_{2} \\
\text {-totales país- } \\
\text { kilotoneladas }\end{array}$ & $\begin{array}{c}\text { Emisiones } \mathrm{CO}_{2} \text { turismo } \\
- \text { por transporte- } \\
\text { kilotoneladas }\end{array}$ & $\begin{array}{c}\text { Emisiones } \mathrm{CO}_{2} \text { turismo } \\
\text {-por alojamiento y otras } \\
\text { actividades_kilotoneladas }\end{array}$ & $\begin{array}{c}\text { Emisiones } \mathrm{CO}_{2} \text { turismo } \\
\text {-totales-kilotoneladas }\end{array}$ \\
\hline 2010 & 7,243 & 289,72 & 72,43 & 362 \\
\hline 2011 & 7,460 & 298,40 & 74,60 & 373 \\
\hline 2012 & 7,506 & 300,24 & 75,06 & 375 \\
\hline 2013 & 7,871 & 314,84 & 78,71 & 394 \\
\hline 2014 & 7,970 & 318,80 & 79,70 & 383 \\
\hline 2015 & 7,661 & 306,44 & 76,61 & 400 \\
\hline 2016 & 7,999 & 319,96 & 79,99 & 407 \\
\hline 2017 & 8,138 & 325,52 & 81,38 & 441 \\
\hline 2018 & 8,825 & 353,00 & 88,25 & 399 \\
\hline
\end{tabular}

Fuente. Elaboración propia con datos de Emisiones de CO2 Costa Rica, s. f.

De lo anterior se tiene que, en este periodo, Costa Rica experimenta una clara tendencia a incrementar las emisiones tanto por el transporte como por otras actividades asociadas, incluyendo el alojamiento ${ }^{3}$. El dato más reciente - 2018 - indica que el turismo aporta 441 kilotoneladas de emisiones de CO2, lo que representa, aproximadamente, un $5 \%$ del total de emisiones del país, donde solo el transporte aporta el $4 \%$, mientras actividades de alojamiento y otras aportan el $1 \%$.

Se ha mencionado que la actividad turística en Costa Rica está estrechamente vinculada con las áreas de conservación existentes. El Minaet (2015) reporta que el $26 \%$ de la superficie continental y el $3 \%$ de la zona marina se encuentran bajo alguna forma de protección, entre las que se pueden mencionar parques nacionales, refugios de vida silvestre, reservas forestales y zonas protectoras, entre otras.

Para el 2018 arribaron un total de 2959869 extranjeros — vía marítima, aérea y terrestre-, de los cuales un 27,4\% visitaron alguna de las áreas de conservación en Costa Rica. En la tabla 2 se observa que el tipo de área protegida con mayor visitación de extranjeros corresponde a los parques nacionales $-94 \%$-.

${ }^{3}$ El incremento en las emisiones está claramente relacionado con el incremento sostenido en la visitación y los viajes internos y externos. 
Tabla 2. Costa Rica. Cantidad de turistas extranjeros por áreas de conservación, 2018

\begin{tabular}{|l|c|}
\hline \multicolumn{1}{|c|}{ Tipo de área de conservación } & Cantidad de turistas \\
\hline Parque nacional & 1083756 \\
\hline Refugio nacional de vida silvestre & 28697 \\
\hline Reserva biológica & 25076 \\
\hline Reserva forestal & 137 \\
\hline Reserva natural absoluta & 9649 \\
\hline Zona protectora & 711 \\
\hline Otras áreas silvestres protegidas & 8594 \\
\hline \multicolumn{2}{|c|}{ Total } \\
\hline
\end{tabular}

Fuente. Elaboración propia con datos de ICT, s. f. b.

Entre los parques nacionales más visitados se encuentran Manuel Antonio, seguido en importancia por Tortuguero, ambos con atractivos de montaña y playa, y en tercer lugar el Volcán Irazú, que exhibe una espectacular laguna y vista al Valle Central del país (ICT, s. f. b).

Dada la cantidad de visitas a las áreas protegidas — más de un millón de personas en el 2018_, el turismo ejerce una fuerte presión sobre las áreas de conservación, de manera que las regiones más afectadas son Guanacaste, Región Huetar Norte y Tortuguero, mientras que las regiones bajo presión media son los manglares, el bosque húmedo tropical y el bosque seco (Minae et al., 2018).

Los turistas visitan, además, otros sitios para su disfrute en el país. Durante el periodo 2016-2018 el ICT realizó una encuesta a extranjeros en los diferentes aeropuertos para conocer las actividades que deseaban realizar en el país. Los resultados indican que, aproximadamente, un $74 \%$ desean disfrutar de sol y playa, un $64 \%$ ecoturismo y un $58 \%$ aventura - ríos y montaña-. Todas estas actividades se realizan en espacios naturales de carácter público —áreas de conservación-o privado.

Esta gran cantidad de personas adicionales en el territorio costarricense presiona el uso de los recursos ${ }^{4}$ para su atención. Así, por ejemplo, durante el periodo 2005-2015 ha incrementado la extracción de agua desde las fuentes existentes de agua subterránea y superficial para el uso en la industria turística en el país, pasando de 4,86 mill m3/año en el 2010 a 18,4 mill m3/año en el 2015 (INEC, 2017).

En los párrafos anteriores se ha mostrado no solo la importancia que tiene la actividad turística para la economía costarricense, también se ha pretendido explicar las presiones que está ejerciendo sobre los diversos ecosistemas existentes. En el siguiente apartado se clarifica cuáles instrumentos se han utilizado para enfrentar el cambio climático a raíz de las presiones que ejerce sobre los ecosistemas. Estas medidas buscan la sostenibilidad actual y futura de la actividad turística.

${ }^{4}$ No se obtuvieron datos sobre el consumo de energía del sector turístico. 


\section{Estrategias para la adaptación y mitigación al cambio climático del sector turístico}

$E^{1}$

sector turístico es una actividad desarrollada mediante mecanismos lineales de producción. Inicia con la etapa de extracción de recursos y pasa por la producción y el consumo hasta ser desechados. A partir de la relación entre el cambio climático y el turismo, explicada en el apartado anterior, este mecanismo de producción es insostenible, ya que contribuye a los procesos de cambio climático $\mathrm{y}$, por ende, incrementa la variabilidad climática de modo tal que afecta el turismo. Lo anterior podría impactar la disponibilidad de recursos naturales y modificar las condiciones atractivas y necesarias en el turismo, imposibilitando posiblemente un adecuado funcionamiento de este a largo plazo.

Ante esta situación, la economía circular se posiciona como una oportunidad y una necesidad de garantizar el buen funcionamiento del turismo en el futuro, en el que existan niveles de sostenibilidad y productividad eficientes. Se asume como primordial el uso eficiente de recursos en los flujos de entrada y salida de los procesos de producción y en su impacto en el medio ambiente.

Este enfoque también posibilita la innovación en las formas de producir y comercializar, tomando como premisa el respeto a los recursos naturales y materiales necesarios para los diferentes procesos. Es por esto que la economía circular y el turismo se posicionan como una oportunidad en busca de nuevas estrategias ante los retos de mitigación y adaptación al cambio climático.

En esta línea de ideas se entiende que la mitigación del cambio climático está relacionada con las acciones o medidas implementadas para disminuir y limitar las emisiones de los gases de efecto invernadero (GEI) o mejorar las condiciones para que los sumideros eliminen de forma adecuada dichos gases de la atmósfera. Por tanto, estas medidas buscan reducir niveles de emisiones de GEI, limitar la nueva liberación de emisiones y resguardar y mejorar los reservorios existentes o crear nuevos sumideros.

Por su parte, la adaptación busca los ajustes necesarios en los comportamientos humanos frente a los distintos entornos, como, por ejemplo, la adaptación al clima. Las medidas de adaptación buscan una disminución de la vulnerabilidad con el objetivo de alcanzar un desarrollo sostenible, incorporando aspectos de planeación, manejo ambiental y de desastres.

Así, mitigación y adaptación son objetivos interrelacionados. La adaptación se circunscribe a un destino y contexto local concreto y constituye, a su vez, una actividad estrechamente conectada con las políticas de mitigación. La adaptación reduce los costes de los impactos del cambio climático y, por tanto, las necesidades de mitigación. No obstante, la mitigación siempre será necesaria para evitar cambios irreversibles en el sistema climático y, al mismo tiempo, la adaptación seguirá siendo necesaria debido al cambio climático irreversible como resultado de los aumentos actuales e históricos de GEI. Considerando esta diferenciación, a continuación, se presentan las medidas de adaptación y mitigación que ha llevado a cabo Costa Rica en el propósito de enfrentar el cambio climático sobre el sector turístico.

\subsection{Medidas de adaptación del sector turístico}

Como parte de las medidas de adaptación, la política pública busca «reforzar la resiliencia al cambio climático en los distintos ámbitos naturales y socioeconómicos» (Minaet y IMN, 2018, p. 31). La resiliencia se entiende, entonces, como:

la capacidad de los sistemas humanos y naturales no solo de hacer frente a los eventos adversos y superarlos, preservando y restaurando las 
estructuras y funciones básicas, sino también de ser transformados positivamente por esos eventos; es decir, es una capacidad transformativa que abarca la posibilidad de generar cambios en el entorno amenazante. (Minaet y IMN, p. 32)

El reforzamiento de la resiliencia se busca a través de la conectividad entre ecosistemas para el resguardo de refugios climáticos, de manera que las áreas protegidas y los corredores biológicos se constituyen en el instrumento para la ampliación en la conectividad de ecosistemas que garanticen la protección de especies, de los ciclos biofísicos y, por supuesto, del ciclo hídrico. En esta tarea, la estrategia nacional de biodiversidad busca la conservación in situ y la conectividad-resiliencia de las áreas conservadas. Reconoce que el Sistema de Áreas Silvestres Protegidas (SASP) y los ecosistemas marinos, terrestres y dulce-acuícolas se constituyen en el instrumento que permite la adaptación y la resiliencia frente a la variabilidad y el cambio climático. Adicionalmente, busca la importante integración de la biodiversidad en el desarrollo social y económico, en el cual las actividades turísticas son fundamentales ${ }^{6}$.

La estrategia incluye, además, otras acciones en materia de regularización del patrimonio natural del Estado y el ordenamiento territorial y del espacio marino ${ }^{7}$. Así, se busca ampliar el enfoque de construcción de la resiliencia desde una visión centrada en los Objetivos de Desarrollo Sostenible (ODS). En concreto, la estrategia de adaptación incluye:

- Fomento de las condiciones para la resiliencia de los sistemas humanos y naturales mediante la planificación territorial, marina y costera. Para esto se requiere generar información a partir de sistemas de registro, el monitoreo, la previsión de factores climáticos e hidrológicos y sus impactos —servicios climáticos—, así como la capacidad de tomar decisiones en materia de adaptación (Minae y IMN, 2018, p. 61). Esto implica incluir criterios y lineamientos de adaptación al cambio climático en los instrumentos de planificación sectorial, regional y de ordenamiento territorial, marino y costero a distintas escalas.

- Servicios públicos adaptados e infraestructura resiliente. Se busca que la inversión construya infraestructura energética, vial, de telecomunicaciones, agua, salud y educación con capacidad para sustentar los servicios que presta a la sociedad (Minae y IMN, 2018).

- Sistemas productivos adaptados y ecocompetitivos. Pretende promover la transformación productiva mediante la innovación en la producción y la sensibilización de los consumidores -modificar hábitos de consumo hacia productos sustentables- $\mathrm{Al}$ mismo tiempo, aprovechar las certificaciones e incentivos ambientales existentes para promover el cambio. Se busca, además, promover y fortalecer las alianzas público-privadas para intercambios de conocimiento y nuevas formas de hacer negocios. Estas acciones forman parte de esa transformación productiva que se orienta hacia la economía circular. En seguida, se presentan algunos indicadores de medidas para la adaptación al cambio climático con enfoque de economía circular en los que resulta relevante el aporte a objetivos estratégicos para la sostenibilidad de los ecosistemas y de la sociedad en conjunto.

\footnotetext{
${ }^{5}$ Se refiere a lugares con menor cambio relativo en el clima futuro.

${ }^{6}$ Estas metas son congruentes, además, con los objetivos de desarrollo sostenible 13, 14 y 15.

${ }^{7}$ Los programas y proyectos para implementar en la estrategia de biodiversidad cuentan con 100 millones de dólares y se buscan recursos adicionales para cumplir las metas propuestas.
} 
Tabla 3. Costa Rica: indicadores de economía circular y objetivos estratégicos para la adaptación al cambio climático — varios años-

\begin{tabular}{|c|c|c|}
\hline Indicadores & Valor & Objetivo estratégico \\
\hline $\begin{array}{l}\text { Cantidad de corredores biológicos } \\
\text {-2017_ }\end{array}$ & $44-15997 \mathrm{~km}-$ & $\begin{array}{l}\text { Resiliencia de los sistemas humanos y } \\
\text { naturales. }\end{array}$ \\
\hline $\begin{array}{l}\text { Incremento de la superficie forestal } \\
-2016 \text { - }\end{array}$ & $54 \%$ — 437 000 hectáreas- & $\begin{array}{l}\text { Resiliencia y conservación de servicios } \\
\text { ecosistémicos. }\end{array}$ \\
\hline $\begin{array}{l}\text { Cantidad de cantones con ordenamiento } \\
\text { territorial }\end{array}$ & 40 & Comunidades sostenibles. \\
\hline $\begin{array}{l}\text { Comunidades con turismo rural } \\
\text { comunitario }\end{array}$ & 40 - Cooprena -+20 -Actuar- & $\begin{array}{l}\text { Sistemas productivos adaptados y } \\
\text { ecocompetitivos. }\end{array}$ \\
\hline Organizaciones con turismo sostenible & 397 & Nuevas formas de negocios. \\
\hline $\begin{array}{l}\text { Porcentaje de agua tratada por } \\
\text { saneamiento - } 2019-\end{array}$ & $15 \%$ & $\begin{array}{l}\text { Servicios públicos adaptados e } \\
\text { infraestructura resiliente. }\end{array}$ \\
\hline Cobertura de agua —2019_ & $99,6 \%$ & $\begin{array}{l}\text { Servicios públicos adaptados e } \\
\text { infraestructura resiliente. }\end{array}$ \\
\hline Cobertura de electricidad -2019— & $99,7 \%$ & $\begin{array}{l}\text { Servicios públicos adaptados e } \\
\text { infraestructura resiliente. }\end{array}$ \\
\hline Cobertura de Internet - 2019- & $86,3 \%$ & $\begin{array}{l}\text { Servicios públicos adaptados e } \\
\text { infraestructura resiliente. }\end{array}$ \\
\hline
\end{tabular}

Fuente. Elaboración propia con datos de Sinac, 2017; FAO, 2016; ENAHO, 2019; Universidad de Costa Rica - UCR, 2018.

Finalmente, la política de adaptación incluye el Proyecto BID Parques que se ha ejecutado desde el 2011, con tres objetivos: inversiones para el desarrollo turístico sostenible, el fortalecimiento de la planificación y la gestión sostenible del turismo — con la elaboración de planes de manejo-, y el fortalecimiento institucional del Sinac. Este programa tiene la debilidad de no haber aportado elementos para enfrentar el cambio climático que permitan asegurar la sustentabilidad del turismo dentro de las áreas de conservación (ICT y Turismo Sostenible, 2017). Así mismo, este proyecto financió asistencia técnica para apoyar a las municipalidades en la gestión sostenible del turismo. Entre los aspectos incluidos se encuentran:

planes de ordenamiento y desarrollo urbano; planes de manejo de desechos sólidos, aguas servidas y control de la contaminación ambiental; la promoción y establecimiento de mecanismos e instrumentos financieros que permitan el incremento de los ingresos municipales por concepto de las actividades turísticas vinculadas a las áreas protegidas; y capacitación a las municipalidades para que puedan participar en el proyecto. (Sinac, 2017, p. 19)
Entre las municipalidades participantes y beneficiadas con este proyecto se cuentan: Talamanca, San Carlos, Liberia, Guatuso, Los Chiles, Golfito, Quepos y Oreamuno, para un total de ocho gobiernos locales con mayores capacidades de desarrollar el turismo sostenible en sus comunidades. Estos municipios representan, aproximadamente, el $10 \%$ de las municipalidades del país, pero, además, son los territorios con mayor oferta turística y atractivos naturales.

El Proyecto BID Parques identificó una importante cantidad de encadenamientos turísticos y redes de colaboración de entes públicos y comunidades, orientados todos al desarrollo del turismo sostenible. En la tabla 4 se presentan los detalles; se puede observar que las oportunidades pasan por las redes y las alianzas público-privadas, y las implicaciones que esto puede tener desde el punto de vista de nuevos negocios, nuevas formas de producir los servicios turísticos y nuevos mecanismos para la comercialización de servicios turísticos y otros. Ofreciendo así, además, oportunidades para la adaptación al cambio climático. 
Tabla 4. Costa Rica: oportunidades y encadenamientos para la adaptación al cambio climático de la actividad turística en áreas de conservación, según parque nacional

\begin{tabular}{|l|l|}
\hline \multicolumn{1}{|c|}{ Área protegida } & \multicolumn{1}{|c|}{ Encadenamientos turísticos potenciales } \\
\hline Parque Nacional Cahuita & $\begin{array}{l}\text { Fortalecimiento de los operadores del área marina —-tour de arrecifes de coral- } \\
\text { en el Parque Nacional Cahuita. }\end{array}$ \\
\hline Parque Nacional Corcovado & $\begin{array}{l}\text { Promoción del destino mediante el Proyecto Caminos de Osa y la unión de las } \\
\text { cámaras de turismo de la zona. }\end{array}$ \\
\hline Parque Nacional Manuel Antonio & Promoción del destino de la zona alta de Quepos. \\
\hline Parque Nacional Marino Ballena & $\begin{array}{l}\text { Fortalecimiento del Destino Red de Turismo Rural de Playa Hermosa y Programa } \\
\text { de Conservación PNMB Reserva Privada Playa Hermosa. }\end{array}$ \\
\hline Parque Nacional Rincón de la Vieja & $\begin{array}{l}\text { Promoción de Destino Rincón de La Vieja y las comunidades en su zona de } \\
\text { influencia mediante el tour operadora de la Asociación de Guías. }\end{array}$ \\
\hline Parque Nacional Volcán Arenal & Promoción de del destino Comunidades del Arenal. \\
\hline Parque Nacional Volcán Irazú & $\begin{array}{l}\text { Circuito cultural-histórico en la región del volcán Irazú mediante la Cámara de } \\
\text { Comercio, Industria, Turismo y Servicios de Cartago. }\end{array}$ \\
\hline Parque Nacional Volcán Poás & $\begin{array}{l}\text { Fortalecimiento del destino mediante la creación de la Asociación de Guías } \\
\text { Locales de la Región del Volcán Poás. }\end{array}$ \\
\hline $\begin{array}{l}\text { Refugio Nacional de Vida Silvestre } \\
\text { Mixto Caño Negro }\end{array}$ & Fortaleciendo el Destino: «Programa Voluntariado Caño Negro». \\
\hline Parque Nacional Tortuguero & Fortalecimiento de la Red de Turismo Rural comunitario de San Francisco. \\
\hline
\end{tabular}

Fuente: Sinac, 2017, p. 26.

Como parte de las tareas que se realizan en las comunidades con miras a fortalecer el turismo aportando elementos para la competitividad, se han establecido diversas alianzas público-privadas (véase la Tabla 5). Interesa mucho destacar que estas alianzas permiten y favorecen la formalización de los emprendimientos, en especial en las zonas rurales, pero además contribuyen a la creación de nuevos mercados y diversifica la oferta turística. Así, por ejemplo, las comunidades rurales han apostado al desarrollo de sus territorios a partir de actividades turísticas particulares, entre las que se pueden mencionar: el turismo rural comunitario, el turismo sostenible y el agroturismo. En todas ellas se establece una interesante combinación de actividades productivas con ganadería, cultivos perenes, especialmente los tours de café o chocolate, mariposarios, pesca, agricultura orgánica y beneficios de café, entre muchos otros, con el objetivo de ofrecer al turista una experiencia adicional de disfrute y convivencia con los lugareños y con los espacios ambientales. 
Tabla 5. Costa Rica: alianzas público-privadas para la sostenibilidad de la actividad turística en zonas rurales

\begin{tabular}{|l|l|}
\hline \multicolumn{1}{|c|}{ Alianzas público-privadas } & \multicolumn{1}{c|}{ Objetivo estratégico } \\
\hline $\begin{array}{l}\text { Alianza para el Fortalecimiento del Turismo Rural } \\
\text { Comunitario -Cooprena R. L., Actuar, Acepesa, } \\
\text { ICT, PNUD_. }\end{array}$ & Desarrollo y fortalecimiento del turismo sostenible. \\
\hline $\begin{array}{l}\text { Organizaciones comunitarias como Cooprena R. } \\
\text { L., Actuar, Acepesa, ICT y PNUD. }\end{array}$ & $\begin{array}{l}\text { Formalización de empresas de turismo comunitario, a fin de } \\
\text { que cuenten a la brevedad con la declaratoria turística. }\end{array}$ \\
\hline $\begin{array}{l}\text { Organizaciones comunitarias como Actuar, } \\
\text { Cooprena e INA. }\end{array}$ & $\begin{array}{l}\text { Jóvenes de comunidades rurales certificados como guías de } \\
\text { turismo nacional. }\end{array}$ \\
\hline $\begin{array}{l}\text { Organizaciones comunitarias como Cooprena e } \\
\text { ICE }\end{array}$ & Llevar internet a las zonas rurales. \\
\hline
\end{tabular}

Fuente. Elaboración propia con datos de Solano, 2008.

\subsection{Medidas de mitigación del cambio climático}

El sector turístico costarricense ha tomado tres medidas de mitigación al cambio climático, entre ellas el Programa Bandera Azul Ecológica y el Programa de Sello de Calidad Sanitaria y la Certificación de Sostenibilidad Turística.

El Programa Bandera Azul Ecológica (PBAE) tiene como objetivo promover la organización de comités locales para enfrentar el cambio climático y mejorar condiciones sanitarias. Este galardón se ofrece al sector agropecuario, a los centros educativos, las comunidades, la construcción sostenible, espacios naturales protegidos, eventos especiales, hogares sostenibles, microcuencas, municipalidades y playas, entre otros.
Además, premia el trabajo voluntario para crear las condiciones que permitan la resiliencia y la capacidad adaptativa en la gestión organizacional. En este marco, las instituciones públicas han reducido el uso de agua, la electricidad, los combustibles fósiles, de papel y plástico, así como han iniciado programas de compras sustentables. También la implementación de acciones para el reciclaje de materiales y el reúso ${ }^{8}$.

Este programa otorga distinciones en cinco niveles que se traducen en estrellas, determinados por una serie de lineamientos. En la tabla 6 se presentan algunos indicadores de economía circular calculados para espacios de playa a partir de los resultados del Programa Bandera Azul Ecológica?.

\footnotetext{
${ }^{8}$ No se cuenta con estadísticas e indicadores.

${ }^{9}$ De momento los indicadores no muestran información que permita determinar avances o retrocesos debido a la falta de información para diferentes periodos. Esta circunstancia limita el análisis, sin embargo, es un primer paso para futuros estudios.
} 
Tabla 6. Costa Rica: cálculo de indicadores de economía circular a partir de los resultados del PBAE

\begin{tabular}{|l|c|l|}
\hline \multicolumn{1}{|c|}{ Indicador de economía circular } & Cantidad de playas & \multicolumn{1}{c|}{ Objetivo estratégico } \\
\hline Calidad del agua para consumo humano & 89 & Salud, bienestar, ciudad limpia. \\
\hline Vertidos industriales tratados & 89 & Conservación de ecosistemas y especies. \\
\hline Aguas residuales tratadas & 89 & $\begin{array}{l}\text { Conservación de recurso hídrico para reutilización } \\
\text { propia y de otras actividades. }\end{array}$ \\
\hline Educación ambiental & 89 & Educación a las comunidades y turistas. \\
\hline Separación y reciclaje de desechos sólidos & 1 & $\begin{array}{l}\text { Reducción en el uso de materias provenientes de los } \\
\text { ecosistemas y reutilización de materias. }\end{array}$ \\
\hline Plan de manejo de áreas protegidas & 1 & $\begin{array}{l}\text { Conservación de servicios ecosistémicos y } \\
\text { comunidades sostenibles. }\end{array}$ \\
\hline Policía Turística & 5 & Comunidades sostenibles y seguras. \\
\hline
\end{tabular}

Fuente. Elaboración propia con datos del PBAE, 2018.

Un segundo mecanismo es el Programa de Certificaciones y Responsabilidad Social Turística (CST) del ICT, el cual otorga un reconocimiento a la gestión empresarial y organizacional en pro de la mitigación de los impactos de su operación, con el objetivo de fortalecer la actividad turística sostenible. Además, busca utilizar productos biodegradables, reciclables, reutilizables, naturales, dispositivos eficientes para el ahorro de energía y agua, el manejo de desechos e información, entre otros. En el caso de los restaurantes $y$ otros establecimientos se consideran los siguientes aspectos. Las empresas certificadas en el 2016 con este programa fueron 351 , entre las cuales se encuentran 234 empresas de hospedaje, 82 operadoras de tours, siete empresas de renta de vehículos, 12 parques temáticos sostenibles, seis empresas gastronómicas sostenibles y diez operadoras de tours Marino-Costeros. La debilidad que se puede anotar de este instrumento es que no permite conocer el peso del tipo de actividades que realizan las empresas para obtener la certificación, lo que limita las posibilidades de construir indicadores de desempeño. De estas, el $9 \%-351$ - poseen una estrella, el $21 \%$ dos estrellas, el $23 \%$ tres estrellas, el $24 \%$ cuatro estrellas y el $23 \%$ cinco estrellas. Lo anterior evidencia una oportunidad de mejora en incrementar los niveles de sostenibilidad.

El tercer instrumento es el Programa de Sello de Calidad Sanitaria (PSCS), que busca incentivar a los establecimientos a mantener y mejorar de manera integral el uso y consumo del agua. Este programa otorga bandera celeste a entes operadores y centros de salud y bandera verde a hoteles, restaurantes, centros de recreación y otros establecimientos.

La participación en este programa ha permitido mejorar la cobertura de agua de calidad potable en todo el país, fomentar susceptibilidad ambiental para proteger las fuentes de agua, incrementar los programas de control de calidad, relacionar el PBAE y el PSCS y mejorar la salud yla calidad de vida de un alto porcentaje de la población costarricense (AYA, 2013). En la tabla 7 se anotan algunos indicadores calculados a partir de los resultados de la implementación de medidas para la mitigación ante el cambio climático con la combinación de los instrumentos. 
Tabla 7. Costa Rica: indicadores de economía circular a partir de la implementación del PBAE y el PSCS

\begin{tabular}{|l|c|l|}
\hline \multicolumn{1}{|c|}{ Indicador } & Cantidad de establecimientos & \multicolumn{1}{c|}{ Objetivo estratégico } \\
\hline Uso de agua potable & 7 & Salud, bienestar, ciudad limpia. \\
\hline Controles de consumo de agua potable & 2 & Conservación de recurso hídrico. \\
\hline Campañas de reforestación & 2 & $\begin{array}{l}\text { Conservación de servicios ecosistémicos y } \\
\text { comunidades sostenibles. }\end{array}$ \\
\hline Protección del agua & 2 & $\begin{array}{l}\text { Conservación de recurso hídrico para } \\
\text { reutilización propia y de otras actividades. }\end{array}$ \\
\hline
\end{tabular}

Fuente: elaboración propia con datos de AYA, 2013.

Por su parte, con respecto al sello de calidad sanitaria entregado a algunos restaurantes, solo el $50 \%$ posee controles de consumo de agua y el $77 \%$ de los hoteles. Estos indicadores muestran poco avance en términos de los Objetivos del Desarrollo Sostenible, en relación con el uso del agua, así como muestran oportunidades de mejora para la sostenibilidad del sector turístico.

\section{Discusión de resultados}

$\mathrm{L}$ a adaptación al cambio climático por parte de los servicios de turismo reduce los costes de los impactos del cambio climático y, por tanto, las necesidades de mitigación. Ambas acciones constituyen un proceso iterativo y continuo para reducir la probabilidad y la magnitud de los efectos nocivos causados por el cambio climático.

Es importante reconocer que la adaptación al cambio climático en el contexto del desarrollo de los territorios incluye entender que la adaptación tiene lugar a distintos niveles, pues la implementación ocurre, normalmente, a nivel del destino, empresas o proyectos. Esto se puede observar fuertemente en las comunidades que han implementado nuevas formas de hacer negocios en el sector turístico a partir de la alianzas público-privadas, privadas-privadas y la política pública implementada.

Además, la adaptación es un proceso que debe incluir tareas de implementación, monitoreo, evaluación y ajuste. Así, las políticas sectoriales deben territorializarse, es decir, incluir efectivamente las particularidades de cada localidad o región y trascender la centralización institucional y el enfoque sectorial. Con este propósito se han mostrado avances importantes, sin embargo, es aún un reto para muchos gobiernos locales y comunidades orientar políticas específicas para el desarrollo del turismo sostenible.

Lo anterior conlleva a reconocer, además, que la política de adaptación en Costa Rica no tiene acciones explícitas para el sector turismo, sino que se beneficia de forma directa a través de las acciones de conservación y resiliencia de las áreas de conservación. Los programas de certificación del ICT y los sellos que buscan sostenibilidad no han mostrado resultados profundos en esta tarea. En este sentido, se puede afirmar que el turismo es uno de los sectores menos preparados para los riesgos y las oportunidades que plantea enfrentar el cambio climático; y los programas de mitigación y adaptación presentados constituyen los primeros esfuerzos para avanzar en el fortalecimiento de capacidades para las empresas, las comunidades y los gobiernos a fin de enfrentar el cambio climático. El enfoque de la política es todavía menos preventivo y más reactivo.

Asegurar que el turismo en Costa Rica ofrece una oportunidad inmejorable para enfrentar el cambio climático se basa en la estrecha vinculación del turismo con los ecosistemas existentes y su política 
de conservación. Los mecanismos para mejorar y fortalecer la capacidad de resiliencia de los espacios naturales se traducen en acciones para la adaptación al cambio climático que favorecen los servicios de turismo receptor.

En tanto las áreas protegidas de Costa Rica continúen ofreciendo servicios ecosistémicos culturales y recreativos de calidad, la actividad turística será sustentable desde el punto de vista ambiental. Sin embargo, esta relación no siempre se muestra tan clara; por el contrario, las políticas evidencian carencias para enfrentar el cambio climático por parte del sector y los resultados de las acciones realizadas hasta la fecha no convencen en su efectividad para garantizar adaptación y mitigación.

La información existente sobre el desempeño ambiental de las empresas que atienden al turismo receptor es escasa, incompleta y ofrece poco potencial para construir indicadores para varios años que contribuyan con el análisis de su sostenibilidad actual y futura. En este particular existen grandes oportunidades de mejora para generar la información adecuada y evaluar el comportamiento del sector y los niveles de avance o retroceso que conduzcan a procesos productivos menos lineales.

Las posibilidades de mejora deben partir de la formulación de política pública explícita para la adaptación y mitigación del sector turismo y no solo dirigida a los espacios naturales que explotan los servicios ecosistémicos ofrecidos por la biodiversidad que posee el país.
Desde el punto de vista de la política pública, se presenta una paradoja. Por una parte, la protección de las áreas de conservación, así como la biodiversidad y los recursos que alberga - especialmente el agua-, con la consecuente retribución que estas medidas tienen sobre el reforzamiento de la resiliencia de estos espacios ambientales, Por otra parte, la promoción $y$ el continuo crecimiento de las exportaciones de turismo receptor, actividad fundamental para la economía costarricense pero que contribuye de manera importante a la contaminación y la pérdida de capacidad de regeneración de los espacios ambientales apropiados para recreación y turismo.

La paradójica condición en que se encuentra el turismo en Costa Rica obliga a la industria turística a asumir la responsabilidad individual y colectiva de tomar acciones de adaptación y mitigación que garanticen en el corto, mediano y largo plazo la sustentabilidad de una actividad tan importante desde el punto vista socioeconómico y ambiental.

La revisión de estrategias orientadas a la adaptación y mitigación para enfrentar el cambio climático y hacer sostenible la actividad turística en el país permite evidenciar que, en la medida en que estas acciones tengan éxito, será estratégico el papel del sector a fin de hacer frente al cambio climático por parte la economía en su conjunto. De esta manera, si una de las principales fuentes de riqueza de la economía costarricense, como lo son los servicios de exportación turística, desarrollan mecanismos de adaptación y mitigación para el cambio climático, se explica la importancia estratégica que tiene el sector desde la política nacional para enfrentar el cambio climático. 


\section{Referencias}

AYA. (Enero de 2013). Programa Sello de Calidad Sanitaria a Restaurantes, Hoteles, Centros de recreación y otros establecimientos. Manual de Procedimientos. Costa Rica: Instituto Costarricense de Acueductos y Alcantarillados. Laboratorio Nacional de Aguas. Recuperado de https://bit. ly/3nYk19r

Blanco-Salas, K. (2015). Evaluación de las emisiones de gases de efecto invernadero y precursores provenientes de la aviación internacional en Costa Rica. Tópicos Meteorológicos y Oceanográficos. 14, 41-49. Recuperado de https://bit. ly/3g2sfuM

Banco Central de Costa Rica - BCCR. (s. f.). Cuenta satélite de turismo. Recuperado de https://bit.ly/2JbYf34

Comex. (17 de mayo de 2019). Costa Rica: IED por actividad económica de destino. Recuperado de https://bit.ly/3m9W3YB

Emisiones de CO2 Costa Rica 2018. (s. f.). Datosmacro.com. Recuperado de https://bit.ly/2V6t3F8

FAO (2016). Costa Rica evidencia un aumento del 54\% en su superficie forestal. Recuperado de https://bit.ly/3g880vG

Instituto Costarricense de Turismo - ICT. (s. f. a). Principales actividades realizadas por los turistas. Recuperado de https:// bit.ly/3fDAsoG

Instituto Costarricense de Turismo - ICT. (s. f. b). Cifras turísticas. Recuperado de https://bit.ly/2JfM2KW

Instituto Costarricense de Turismo - ICT, Turismo Sostenible. (2017). Plan Nacional de Desarrollo Turístico de Costa Rica 2017-2021. Recuperado de https://bit.ly/2JdV1w7

Instituto de Estadística y Censos - INEC. (2017). Datos de indicadores claves para la gestión integrada del recurso hídrico (GIRH). Recuperado de https://bit.ly/3nZISd1

Instituto Nacional de Estadística y Censo - INEC. (2019). Encuesta Nacional de Hogares (ENAHO). Recuperado de https://bit.ly/2VsHy6h

Minae (Ministerio de Ambiente y Energía); IMN (Instituto Meteorológico Nacional). (2018). Plan Nacional de Adaptación al Cambio Climático, Costa Rica. Recuperado de https://bit.ly/3fLj5mc
Minae (Ministerio de Ambiente y Energía); Sinac; Conagebio; Fonafifo. (2018). Resumen del Sexto Informe Nacional de Costa Rica ante el Convenio de Diversidad Biológica. Programa de Naciones Unidas para el Desarrollo-Apoyo técnico para que las partes elegibles desarrollen el Sexto Informe Nacional para el CDB (6NR-LAC) Costa Rica. Recuperado de https://bit. ly/3nUCvrm

Minaet (Ministerio de Ambiente, Energía y Telecomunicaciones). (2015). Política nacional de biodiversidad 2015-2030. Recuperado de https://bit.ly/33kWtE9

ONU (Organización de las Naciones Unidas). (2019). Objetivos $y$ metas de desarrollo sostenible. Recuperado de https://bit. $\mathrm{ly} / 39 \mathrm{~ms} 0 \mathrm{sW}$

PBAE (Programa Bandera Azul Ecológica). (2018). Informe galardonados 2018. Recuperado de https://bit.ly/2HJwAWW

Pierce, A.; Ramírez, A.; Sandí, A. (Febrero de 2017). Costa Rica: exportaciones de servicios y sus principales mercados de destino. Departamento de Estadísticas Macroeconómicas, BCCR. Costa Rica. Recuperado de https://bit.ly/39hlofk

Reyes, V. (2016). Situación de los recursos hídricos en Centroamérica. Global Tegucigalpa: Water Partnership Central America. Recuperado de https://bit.ly/39j8rSv

Schatan, C.; Montiel, M.; Romero I. (2010). Cambio climático y retos para el sector turismo de Centroamérica. México: Cepal. Recuperado de https://bit.ly/39dUwgq

Sinac. (2017). Proyecto fortalecimiento programa de turismo en áreas silvestres protegidas (Proyecto BID-Turismo). Recuperado de https://bit.ly/3q23HGF

Sinac. (s. f.). Sistema Nacional de Áreas de Conservación de Costa Rica. Recuperado de https://bit.ly/37fHCM6

Soto, B. (2013). Las condiciones de sequía y estrategias de gestión en Costa Rica. Recuperado de https://bit.ly/367RNmz

Solano, L. (2008). Turismo rural comunitario, iniciativa diferenciada en Costa Rica. Aportes. Agroecoturismo, (135).

Universidad de Costa Rica - UCR. (16 de marzo de 2018). $70 \%$ del agua residual generada por costarricenses carece de tratamiento. Recuperado de https://bit.ly/2JkEGGo 